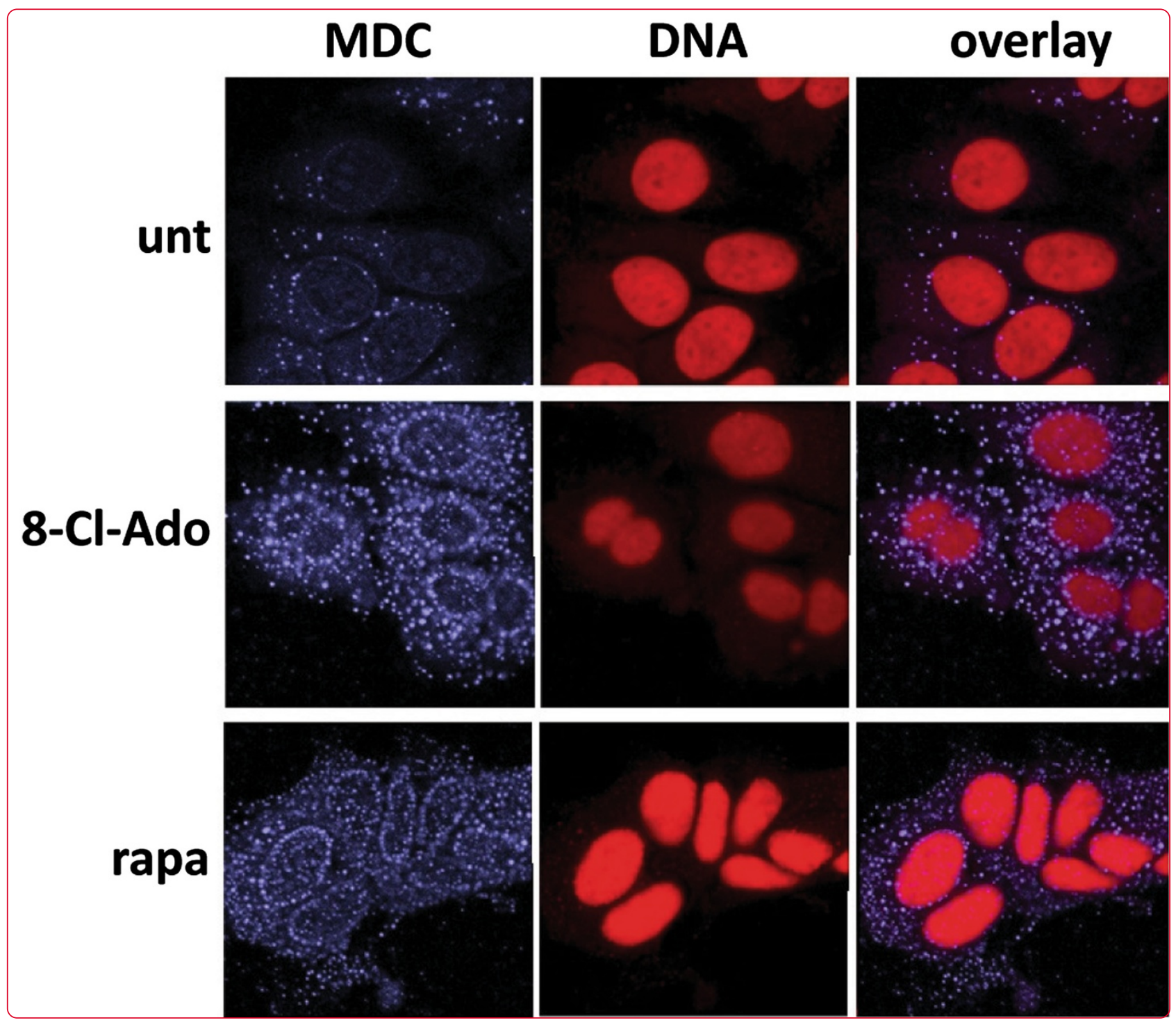

ATP directed agent, 8-chloro-adenosine, induces AMP activated protein kinase activity, leading to autophagic cell death in breast cancer cells

Stellrecht et al. 


\title{
ATP directed agent, 8-chloro-adenosine, induces AMP activated protein kinase activity, leading to autophagic cell death in breast cancer cells
}

\author{
Christine M Stellrecht ${ }^{1,2^{*}}$, Hima V Vangapandu ${ }^{1,2}$, Xiao-Feng Le ${ }^{1}$, Weiqun Mao ${ }^{1}$ and Shujun Shentu ${ }^{1}$
}

\begin{abstract}
Background: 8-chloro-adenosine (8-Cl-Ado) is a unique ribonucleoside analog which is currently in a phase I clinical trial for hematological malignancies. Previously, we demonstrated in breast cancer cells that a 3-day treatment with 10 mM 8-Cl-Ado causes a 90\% loss of clonogenic survival. In contrast, there was only a modest induction of apoptosis under these conditions, suggesting an alternative mechanism for the tumoricidal activity of 8-Cl-Ado.
\end{abstract}

Methods: Cellular metabolism, AMP-activated protein kinase (AMPK) and mammalian target of rapamycin (mTOR) pathway signaling, as well as autophagy induction was evaluated in breast cancer cell lines treated with 8-Cl-Ado. The effects of knocking down essential autophagy factors with small interfering RNA on 8-Cl-Ado-inhibited cell survival was assessed in breast cancer cells by examining apoptosis induction and clonogenic survival. In vivo efficacy of 8-Cl-Ado was measured in two breast cancer orthotopic model systems.

Results: We demonstrate that in breast cancer cell lines, the metabolism of 8-Cl-Ado results in depletion of endogenous ATP that subsequently induces the phosphorylation and activation of the energy sensor, AMPK. This was associated with an attenuation of mTOR signaling and an induction of the phosphorylation of the autophagy factor, Unc51-like kinase 1 on Ser555. 8-Cl-Ado-mediated induction of autophagy was evident by increased aggregates of microtubule-associated protein 1 light chain 3B (LC3B) which was associated with its conversion to its lipidated form, LC3B-II, p62 degradative flux, and increased formation of acidic vesicular organelles. Additionally, transfection of MCF-7 cells with siRNA to ATG7 or beclin 1 provided partial protection of the cells to 8-Cl-Ado cytotoxicity as measured by clonogenicity. In vivo, 8-Cl-Ado inhibited growth of both MCF-7 and BT-474 xenograft tumors. Moreover, in 9 of 22 BT-474 tumors treated with $100 \mathrm{mg} / \mathrm{kg} /$ day 3 times a week, there was an absence of macroscopically detectable tumor after 3 weeks of treatment.

Conclusions: Our data demonstrates that 8-Cl-Ado treatment activates the AMPK pathway leading to autophagy induction of in breast cancer cells, eliciting, in part, its tumoricidal effects. Additionally, 8-Cl-Ado effectively inhibited in vivo tumor growth in mice. Based on this biological activity, we are planning to test 8-Cl-Ado in the clinic for patients with breast cancer.

Keywords: Autophagy, AMPK, mTOR, ATP, 8-chloro-adenosine

\section{Background}

Breast cancer is the most prevalent cancer in women in industrialized countries. Each year more than a half million new cases of breast cancer are diagnosed in the US and Europe. Although in recent years, advances in therapies have contributed to decreased mortality; worldwide nearly

\footnotetext{
* Correspondence: cmstellre@mdanderson.org

'Department of Experimental Therapeutics, University of Texas MD Anderson Cancer Center, Unit 1950, P.O. Box 301429, Houston, TX 77230-1429, USA

${ }^{2}$ Graduate School of Biomedical Sciences, The University of Texas Health Science Center, Houston, TX, USA
}

500,000 deaths are attributed to breast cancer, annually. In addition, toxicity associated with current treatments and the risk of developing secondary cancers [1] highlight the urgent need for new therapies against the disease.

8-chloro-adenosine (8-Cl-Ado) is a unique ribonucleoside analog that is currently in a phase I clinical trial at the UT MD Anderson Cancer Center for the treatment of chronic lymphocytic leukemia (CLL). Previously, we demonstrated this analog is tumoricidal to breast cancer cells [2]. In 
addition, our group and others have shown that 8-Cl-Ado inhibits the growth and survival of numerous other hematological and solid tumor model systems [3-19] but not normal lymphocytes [12] or non-transformed mammary epithelial cells (unpublished data).

Much of our prior work on the cytotoxic effects of 8-Cl-Ado focused on the accumulation of 8-Cl-ATP $[2,8-10,12,20]$ and its incorporation into mRNA [10] preceding an inhibition of transcription $[2,8-10,12,19]$ and poly(A) polymerase $[21,22]$. The net effects of these events lead to an induction of apoptosis [2,8-10,12]. In breast cancer cells, 8-Cl-Ado-induced cytotoxicity is only partially attributed to apoptosis. In addition to the impact on transcription, 8-Cl-Ado-induces a reduction of the intracellular ATP pool $[2,8-10,12]$ and ATP depletion has been associated with apoptosis-independent cell death [23,24].

Within the cell, ATP levels are tightly regulated by AMP-activated protein kinase (AMPK), which functions as a cellular energy sensor [25]. AMP and ATP directly bind and regulate AMPK such that when ATP levels decrease, AMP is allowed to bind and allosterically activate AMPK. Additionally, upstream kinases can then phosphorylate and further activate AMP bound AMPK. Once activated, AMPK promotes events that lead to metabolic switches to restore cellular bioenergy. Significant energy regulating effects of AMPK pertaining to cancer therapeutics is its ability to attenuate growth and protein synthesis by regulating mammalian target of rapamycin (mTOR) pathway and induce autophagy.

AMPK inhibition of mTOR signaling occurs through two pathways. First, AMPK directly phosphorylates and activate tuberous sclerosis protein 2 which is involved in mTOR inhibitory signaling. Second, AMPK has been shown to phosphorylate and inactivate raptor, a member of mTORC1. Both mTORC1 and AMPK regulate autophagy through the phosphorylation of Unc51-like kinase 1 (ULK1). [For a review see ref. [26]]. ULK1 is a mammalian homolog of a yeast autophagy initiating factor, Atg1. Although there has been some discrepancy regarding the specific AMPK phosphorylation sites on ULK1, it is clear that AMPK activates ULK1 while the phosphorylation by mTORC1 inhibits ULK1 activity. AMPK also regulates autophagy through modulation of components of Vsp34 complexes [27].

The events above delineate the mode by which diminished ATP levels can alter cellular processes. Since 8-Cl-Ado treatment diminishes the ATP pool $[2,8-10,12]$, we hypothesize that 8-Cl-Ado treatment will educe AMPK activation and mTORC1 attenuation which will initiate autophagy. Our current investigation further evaluated the cellular metabolism of 8-Cl-Ado and its metabolic effects on bioenergy. Moreover, we examined the mechanism of action of the bioenergy depletion that leads to a nonapoptotic cell death in breast cancer cells.

\section{Results}

8-Cl-Ado accumulation/elimination and effects on energy production

Previously, our group demonstrated that 8-Cl-Ado (Figure 1A) is tumoricidal to primary CLL lymphocytes [12], breast cancer [2], myeloma [17], and mantle cell lymphoma (MCL) [8] cell lines and this cytotoxicity was dependent on the analog's metabolism to its monophosphate form by adenosine kinase [9] followed by triphosphate accumulation. In the breast cancer cell lines, we showed that a 3-day treatment with $10 \mu \mathrm{M} \mathrm{8-Cl-Ado}$ inhibited over 90\% clonogenic survival [2] (Figure 1B). Paradoxically, we demonstrated that such treatments were associated with only a $\sim 30 \%$ induction of apoptosis in both cell lines as measured by annexin V and PI staining [19] (Figure 1C and Additional file 1: Figure S1).

We established that 8-Cl-Ado treatment results in a rapid depletion of ATP within 12-hours which was associated with 8-Cl-ATP accumulation (Additional file 1: Figure S2 and [2]). To examine the impact of 8-Cl-Ado treatment on energy producing metabolic pathways, we analyzed both glycolysis and mitochondrial respiration. Extracellular acidification rate (ECAR), as a measure of glycolysis, and oxygen consumption rate (OCR), for mitochondrial respiratory function, were assessed in both MCF7 and BT-474 cells treated with and without 8-Cl-Ado for $18 \mathrm{hr}$ using a Seahorse XF96 analyzer. Our results indicated that, both basal mitochondrial respiration (Figure 2A, $\mathrm{B}$, and $\mathrm{C}$ ) and glycolysis (Figure 2D) were perturbed by 8-Cl-Ado treatment. The finding of decreased $\mathrm{O}_{2}$ consumption is in keeping with previous data which indicated 8-Cl-Ado may be an inhibitor of mitochondrial complex V, ATP synthase [28]. The alteration in glycolysis may possibly be associated with decreased glucose uptake, which was seen in myeloma cells treated with an 8-Cl-Ado congener compound, 8-amino-adenosine [29]. Interestingly, further assessment of cellular respiratory chain with XF Cell Mito Stress Test assay possibly revealed addition alterations in cellular respiration induced by 8 - $\mathrm{Cl}$-Ado treatment, as OCR was still attenuated even after the addition of an uncoupler, FCCP, to alleviate the dependency of complex I-IV on complex V's transport of electrons across the mitochondrial membrane (Figure $2 \mathrm{~B}$ and $\mathrm{C}$ ). Because tumor cells are known to be sensitive to ATP depletion, we decided to assess the effects of 8-Cl-Ado on ATP levels throughout the 3-day treatment. Our results showed that in BT-474 cells the ATP levels continued to diminish over a 3-day treatment with $10 \mu \mathrm{M}$ 8-Cl-Ado (Figure 2E) while in MCF-7 cells the levels remained below control levels but did show evidence of some recovery by 24 -hours. Additionally, we examined the accumulation of the analog's cytotoxic metabolite, 8-Cl-ATP, over 72-hours. The accumulation of the analog triphosphate inversely paralleled the ATP depletion as it peaked at 

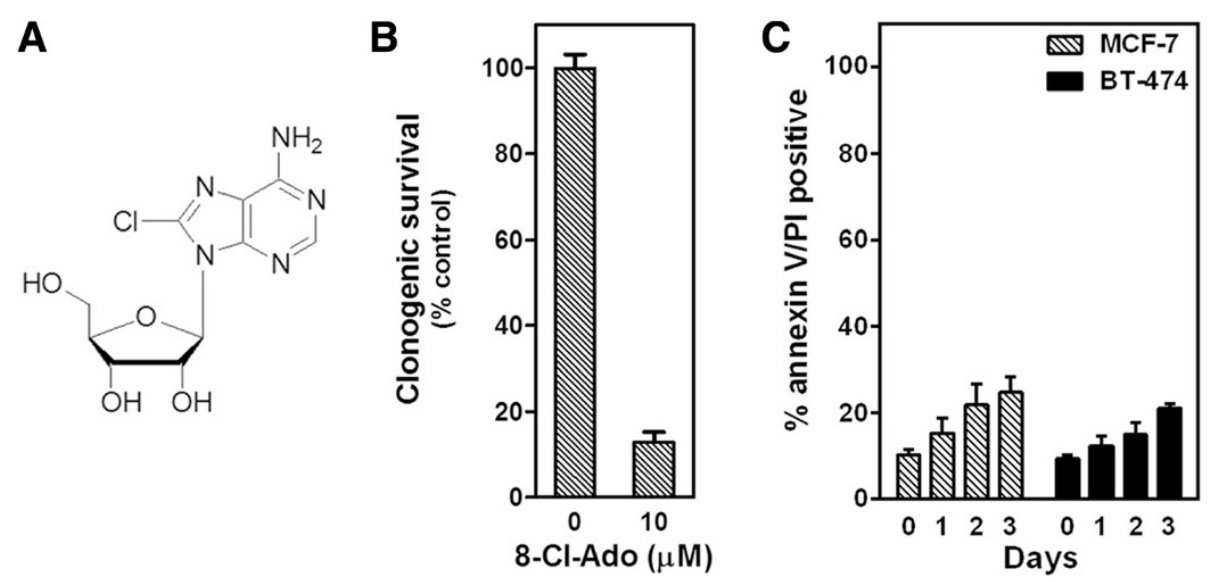

Figure 1 Effect of 8-Cl-Ado on the survival of breast cancer cells. (A) Structure of 8-Cl-Ado. (B) The effects of 8-Cl-Ado on the clonogenic growth of MCF-7 cells. Cells were treated with $10 \mu \mathrm{M}$ 8-Cl-Ado for 3-days, washed with PBS, and cultured in fresh medium for 14-days. Colonies of $>50$ cells were counted under a dissecting microscope. (C) Flow cytometery analysis of annexin $\mathrm{V}$ and PI staining in MCF-7, hatched bars, and BT-474 cells, black bars, treated with $10 \mu \mathrm{M} 8$-Cl-Ado for the indicated times.

24- and 72-hours in MCF-7 and BT-474 cells, respectively (Figure 2F). Since the ratio of 8-Cl-ATP to ATP has been shown to be a determinant of the cytotoxic effect of 8 -Cl-Ado [2,8], the kinetics of this relationship was also examined (Figure $2 \mathrm{G}$ ). We demonstrated that the ratio of the analog triphosphate to normal ATP was highest in MCF-7 cells which rapidly peaked at 12-hours while in BT-474 cells the ratio continually increased until it reached a plateau by 24 -hours. The elimination kinetics of 8-Cl-ATP was also measured by treating the cells with $10 \mu \mathrm{M} 8$-Cl-Ado for 3-days, washing drug off and continued culturing the cells in drug-free medium for another 3-days (Figure 2H). In both lines there appeared to be an initial, more rapid elimination of 8-Cl-ATP after drug removal. If a biphasic elimination kinetics is considered, the 8-Cl-ATP half-lives in MCF-7 cells were 3.8- and 25.5-hours while in BT-474 it was 6.4-hours and $>7$-days. An assessment of the kinetics as a monophasic elimination yields the 8-Cl-ATP half-lives as 5.8 and 11.4-hours for MCF-7 and BT-474, respectively.

\section{8-Cl-Ado induces AMPK activity in breast cancer cells}

The 8-Cl-Ado-induced ATP depletion is expected to increase the AMP to ATP ratio which would lead to activation of AMPK. To determine if 8-Cl-Ado is able to induce AMPK activity, we treated MCF-7 and BT-474 cells with $10 \mu \mathrm{M} 8$ 8-Cl-Ado for various times and assessed changes in p-AMPK (Thr172) levels by immunoblot analysis. The results demonstrated that while total AMPK protein levels were unchanged by 8-Cl-Ado treatment, phosphorylation of AMPK (Thr172) was induced in a time-dependent manner, being readily detected within 7- to 12-hours (Figure 3A). To further assess AMPK activity, we examined the cellular phosphorylation of one of its critical downstream substrates, ACC on Ser79 and showed that AMPK activity is induced within 4-hours of 8-Cl-Ado treatment (Figure 3B). These events occurred in both MCF-7 and BT-474 cells which indicate they do not require p53 as MCF-7 cells have a wild type p53 genotype while BT-474 cells harbor a mutant p53 [30].

\section{Inhibition of mTOR by 8-Cl-Ado}

A significant energy regulating effect of AMPK pertaining to cancer therapeutics is the ability of AMPK to inhibit the mTOR pathway. To determine if the $8-\mathrm{Cl}$ Ado-dependent AMPK induction altered the activity of the mTOR pathway, we assessed the effects of 8-Cl-Ado on Ser792 residue of raptor; an AMPK phosphorylation site on this mTORC1 protein. We determined that $10 \mu \mathrm{M}$ 8-Cl-Ado-treatment readily induced the phosphorylation of raptor Ser792 (Figure 4A) in MCF-7 cells. This was associated with diminished mTOR autophosphorylation on Ser2481 (data not shown). To further assess mTORC1 activity, we examined the phosphorylation status of the mTORC1 target, 4E-BP1, and found 8-Cl-Ado treatment diminished the level of p-4E-BP1 (Ser65), a rapamycin sensitive phosphorylation site [31] and reduced the levels of the slower migrating hyperphosphorylated 4E-BP1 bands (Figure 4B). Overall, these results demonstrate 8-Cl-Ado treatment attenuated mTOR activity in breast cancer cells.

\section{8-Cl-Ado-induced activation of ULK1}

AMPK and mTOR are both able to regulate autophagy through direct phosphorylation of Unc51-like kinase 1 (ULK1), which is the human counterpart of the yeast autophagy initiating factor, Atg1. Although there has been some discrepancy as to the ULK1 phosphorylation sites, 

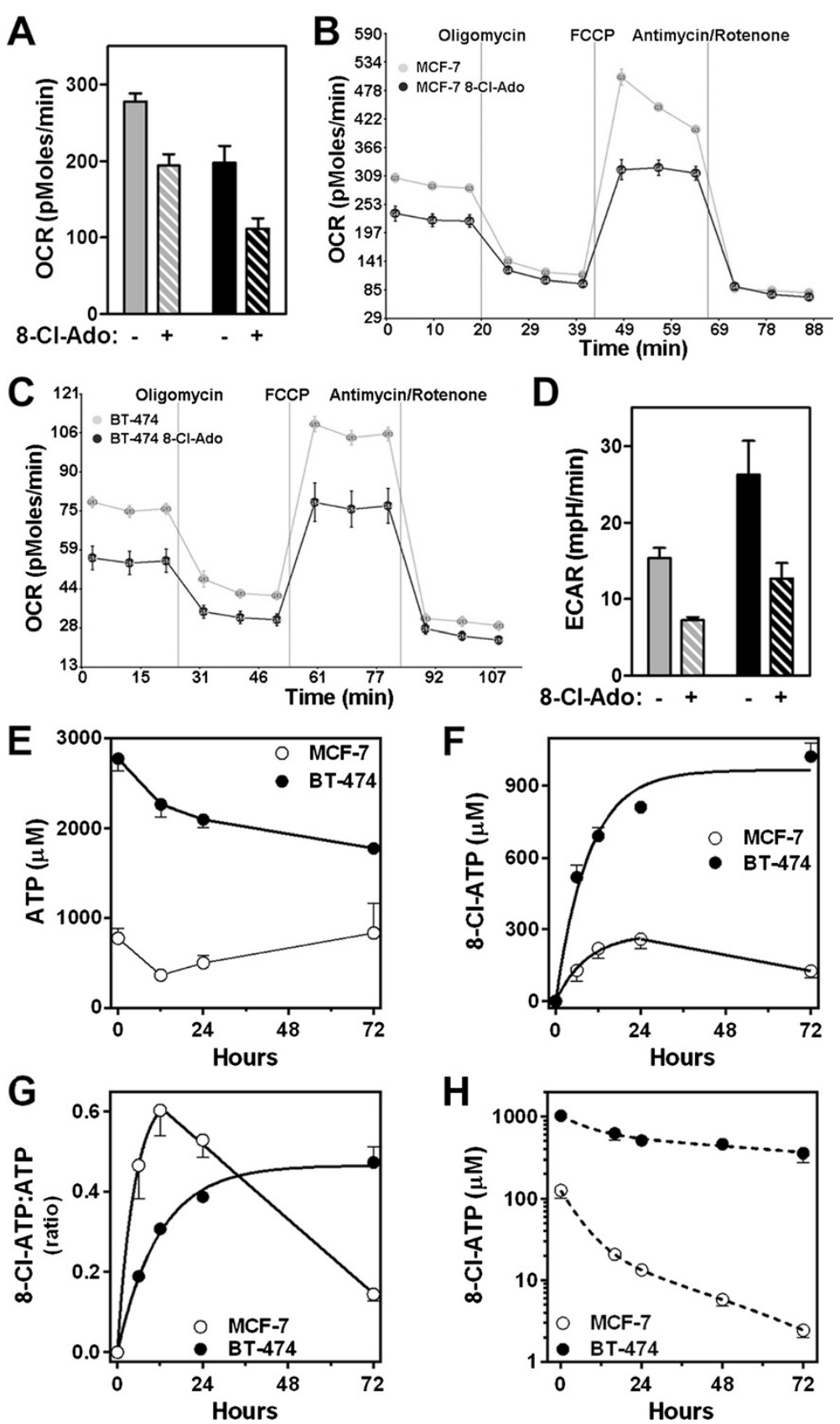

Figure 2 Accumulation and elimination of 8-Cl-ATP and effects on ATP production. (A) $10 \mu \mathrm{M}$ 8-Cl-Ado treatment, hatched bars, perturbs basal OCR as compared to untreated, solid bars, in MCF-7, gray bars, and BT-474 cells, black bars. Effects of altering ETC complexes with the agents, oligomycin, FCCP, antimycin, and rotenone on OCR in (B) MCF-7 and (C) BT-474 cells treated with, black circles, and without, gray circles, $10 \mu \mathrm{M}$ 8-Cl-Ado. (D) $10 \mu \mathrm{M}$ 8-Cl-Ado treatment, hatched bars, reduces basal glycolysis as demonstrated by decreased ECAR in MCF-7, gray bars, and BT-474 cells, black bars. (E) Time dependent depletion of the endogenous ATP pool, (F) the accumulation of 8-CI-ATP, and (G) changes in the 8-Cl-ATP/ATP ratio in MCF-7, 0 , and BT-474 cells, $\bullet$. Cells were treated with $10 \mu \mathrm{M} 8$-Cl-Ado for the indicated times and acid extracts were analyzed by HPLC to measure nucleotide levels. (H) The elimination of 8-Cl-ATP in MCF-7, o, and BT-474 cells, $\bullet$. Cells were treated with $10 \mu \mathrm{M} 8$ 8-Cl-Ado for 3 days, washed with PBS, and cultured in fresh medium. At the indicated times, acid extracts were analyzed as above.

there have been several different reports which indicate AMPK directly phosphorylates ULK on Ser555 [32-35]. We examined the effects of 8-Cl-Ado on the AMPK phosphorylation of this site and determined that $10 \mu \mathrm{M}$ 8-Cl-Ado-treatment induces ULK1 phosphorylation on Ser555 in MCF-7 and BT-474 cells (Figure 5A). 


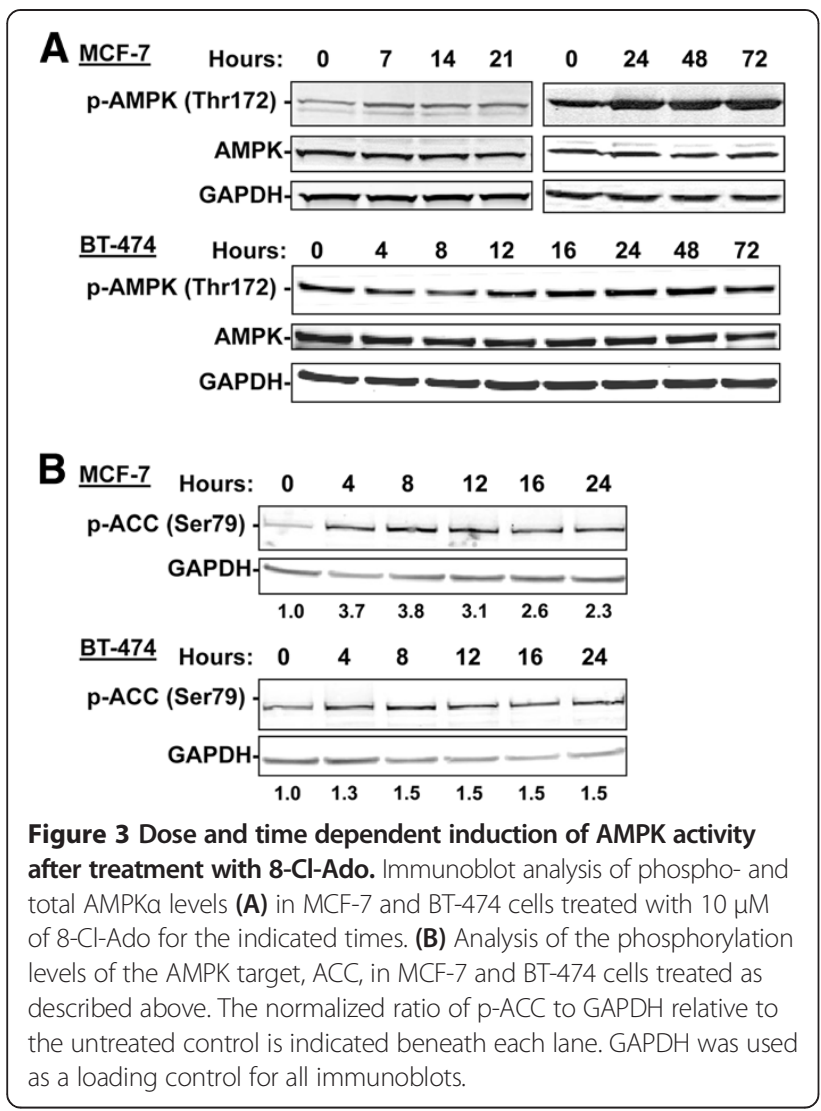

8-Cl-Ado treatment of breast cancer cells elicits autophagy Because both AMPK activation and mTOR inhibition can induce autophagy and 8-Cl-Ado treatment induced ULK1 Ser555 phosphorylation, we investigated whether 8-Cl-Ado would generate an autophagic response. To assess autophagosome formation, we used immunoblot analysis to evaluate lipidation of cleaved LC3B-I to the faster migrating autophagosome marker, LC3B-II. 8-Cl-Ado induced LC3B-I and LC3B-II protein levels in both MCF-7 and BT-474 cells (Figure 5B). Additionally, fluorescent microscopy of MCF-7 and BT-474 cells transfected with a LC3BGFP expression construct, demonstrated that 8-Cl-Ado induced LC3B aggregation (Figure 5C), which further provides evidence of autophagosomes formation. Dynamic changes or flux in p62/SQSTM1 levels are also an indication of autophagy. This is due to the accumulation of p62 bound protein aggregates being sequestered during phagosome formation, followed by depletion because of autolysosomal degradation. 8-Cl-Ado treatment of MCF-7 and BT-474 cells induced an autophagic flux in both LC3B-II and p62 levels (Figure 5B and D).

Demonstration of autolysosome formation was performed by confocal microscopy of live MCF-7 cells stained with monodansylcadaverine (MDC) and syto61 which stains acidic vesicular organelles (AVO) and DNA, respectively (Figure 5E). The mTOR inhibitor, rapamycin, was used

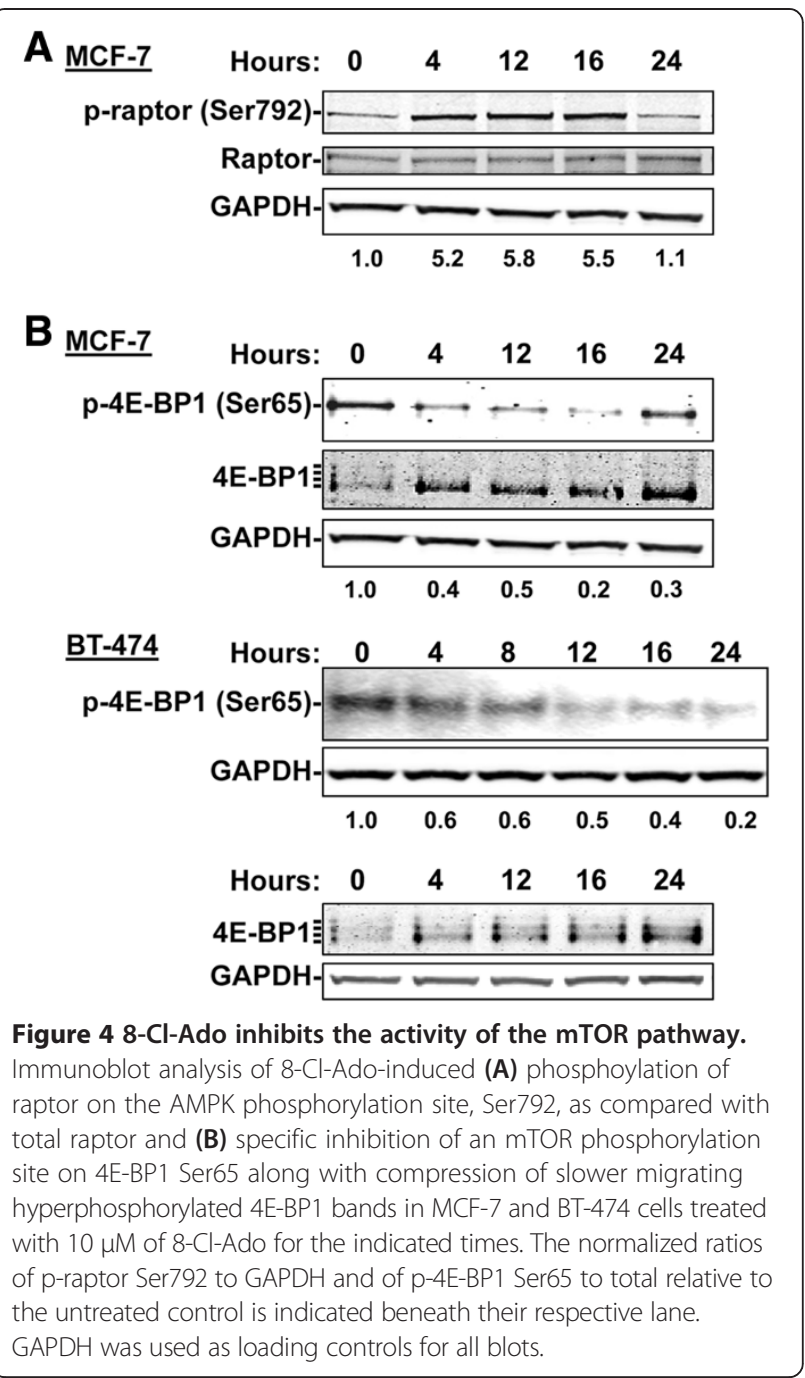

as a positive control. MDC staining of large AVO increased in $10 \mu \mathrm{M} 8$-Cl-Ado treated MCF-7 cells similar to treatment with $50 \mathrm{nM}$ rapamycin. To quantitate the levels of AVO induction, 8-Cl-Ado treated MCF-7 and BT-474 cells were stained with acridine orange and assessed by flow cytometry (Figure 5F and G). Rapamycin and Bafilomycin A1 (Baf) treatment were used as positive and negative controls, respectively. As with the MDC staining, there is an induction of acridine orange staining of AVO in 8-Cl-Ado treated MCF-7 and BT-474 cells to levels similar to treatment with rapamycin. After 3-days of treatment, there were an 18 and $14 \%$ increase in AVO staining with $10 \mu \mathrm{M}$ 8-Cl-Ado in MCF-7 and BT-474 cells, respectively which was comparable to the 14 and $10 \%$ increase seen with $50 \mathrm{nM}$ rapamycin treatment over the same time. Similar results were seen in 8-Cl-Ado treated T47D, SK-BR-3, and ZR-75-1 cells (Additional file 1: Figure S3). Collectively, these results establish that 8-Cl-Ado induces autophagy in breast cancer cells. 


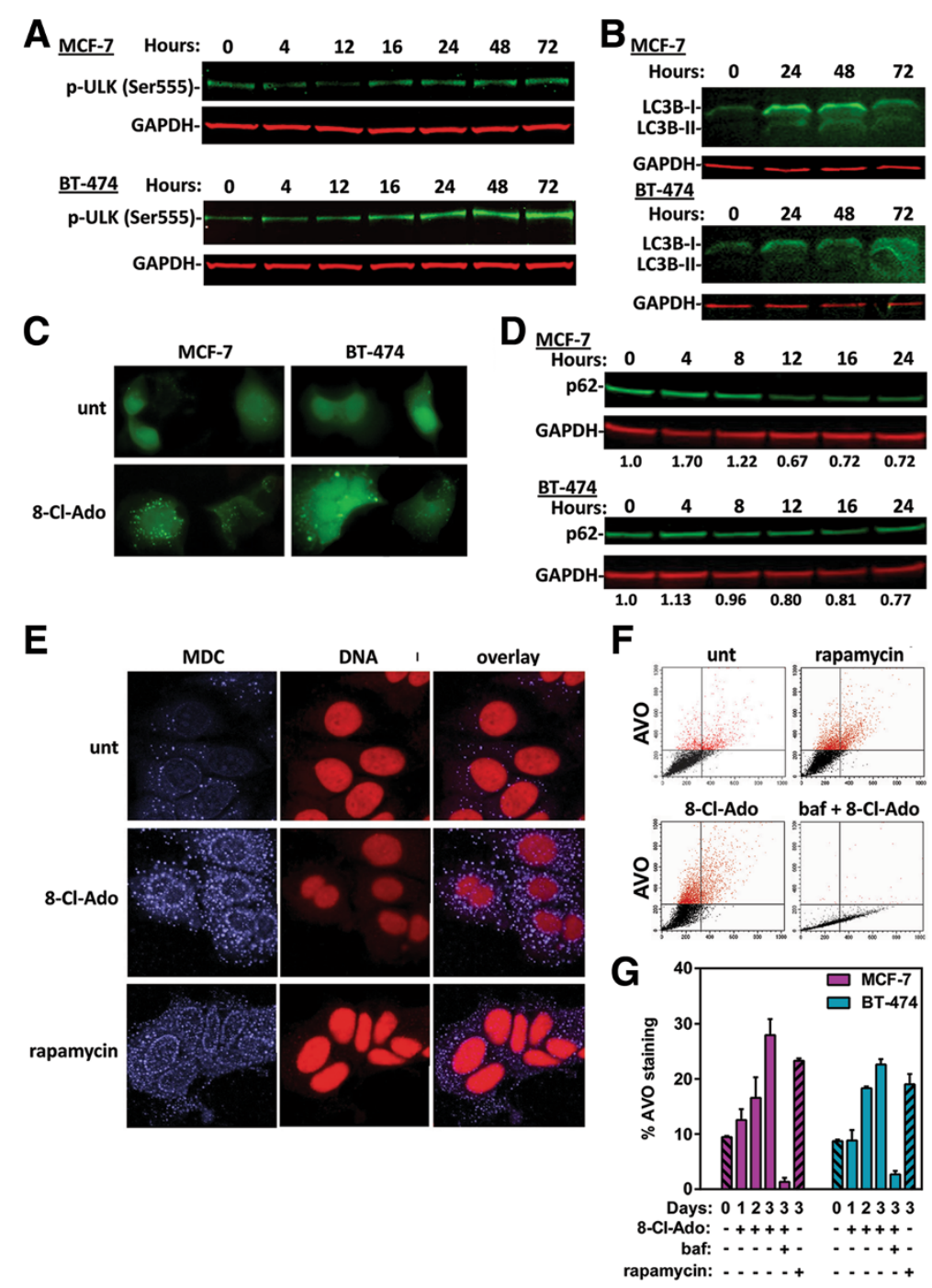

Figure 5 8-Cl-Ado-induces autophagy. Immunoblot analysis of (A) phospho-ULK (Ser555) levels and (B) LC3B-I lipidation to form LC3B-II in MCF-7 and BT-474 cells treated with $10 \mu \mathrm{M}$ of 8-Cl-Ado for the indicated times. (C) Fluorescent microscopy of MCF-7 and BT-474 cells transiently transfected with GFP-LC3B and treated with $10 \mu \mathrm{M}$ of 8-Cl-Ado for 12-hours to assess aggregation of LC3B. (D) Immunoblot analysis of p62 levels in MCF-7 and BT-474 cells treated with $10 \mu \mathrm{M}$ of 8-Cl-Ado for the indicated times. The normalized ratio of p62 to GAPDH relative to the untreated control is indicated beneath each lane. (E) Fluorescent microscopic imaging of autolysosomes. MCF-7 cells were untreated or treated for 2-days with 8-Cl-Ado or rapamycin. Cells were stained with MDC, blue, to visualize AVO and Syto 61 (DNA), red, for nuclei counterstaining. (F) Representative flow cytometery histograms of AVO stained with acridine orange in MCF-7 cells untreated or treated for 3 days with $50 \mathrm{nM}$ rapamycin or $10 \mu \mathrm{M} 8$-Cl-Ado. Baf was added before 30 min prior to staining to neutralize AVO staining. (G) Quantification triplicate experiments of MCF-7 and BT-474 cells treated and analyzed as in $\mathbf{E}$.

\section{Depletion of autophagy proteins diminished 8-Cl-Ado induced cytotoxicity}

Previously, we had noted that with a 3-day treatment of $10 \mu \mathrm{M}$ 8-Cl-Ado there was a $~ 90 \%$ loss of clonogenic survival while the amount of apoptosis induction only reached $\sim 30 \%$ [2] (Figure 1B and C), suggesting there is another mechanism of cell killing occurring in the 8-Cl-Ado treated breast cancer cells. One possibility is through autophagic cell death. To test this hypothesis, we transfected MCF-7 cells with small interfering RNA (siRNA) directed against $A T G 7$, or $B E C N 1$, which are required autophagy factors, and compared 8-Cl-Ado treatment of these cells to MCF-7 cells transfected with siCONT. The targeting siRNAs effectively depleted their respective targets during the 3 days of 8 -Cl-Ado treatment and blocked autophagy induction (Figure 6A and C). Interestingly, although siBECN1 and siATG7 did not alter the extent of 8-Cl-Ado-induced apoptosis (Figure 6A and $\mathrm{B}$ ), they did increase clonogenic survival (Figure 6D and E). These results indicate that $8-\mathrm{Cl}$ Ado cytotoxicity is mediated in part by autophagic cell death. 


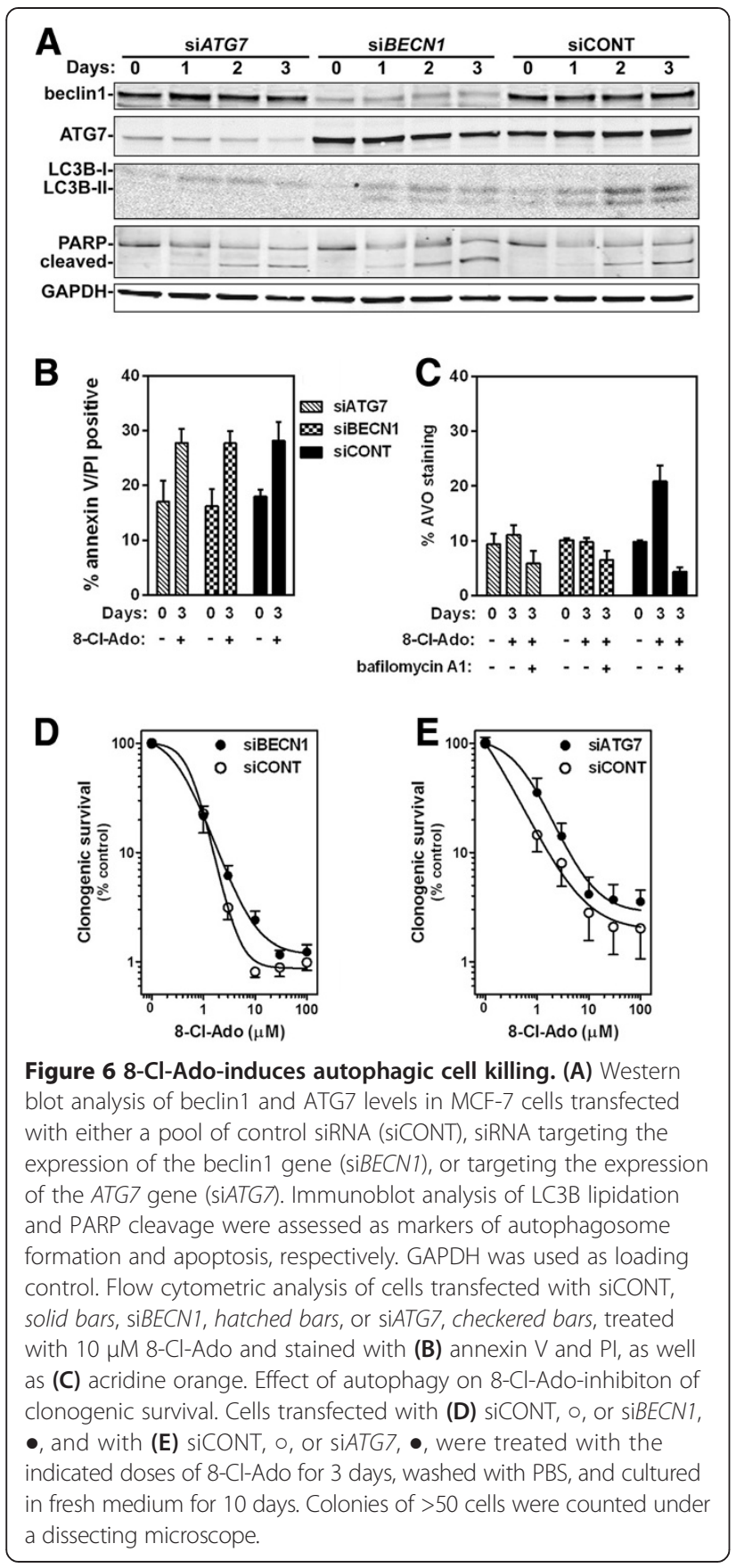

In vivo antitumor activity of $8-\mathrm{Cl}$-Ado in orthotopic breast cancer models

Our studies demonstrated 8-Cl-Ado is tumoricidal to breast cancer cells in cultures. To determine the efficacy of 8-Cl-Ado in vivo we established both MCF-7 and BT474 orthotopic tumors in $\mathrm{nu} / \mathrm{nu}$ mice. Upon tumor formation, mice were treated for 3 weeks with varying doses up to $100 \mathrm{mg} / \mathrm{kg} / \mathrm{d}$ 8-Cl-Ado 3d per week. Previous in cellular pharmacology analyses performed on peripheral blood mononuclear cells from $\mathrm{CD}_{2} \mathrm{~F}_{1}$ mice after i.v. administration of 50 and $100 \mathrm{mg} / \mathrm{kg}$ 8-Cl-Ado, showed the
$1 \mathrm{hr}$ accumulation of 8-Cl-ATP was $\sim 350$ and $\sim 1150 \mu \mathrm{M}$, respectively, [20] which was higher than the accumulation seen in the breast cancer cell lines treated with $10 \mu \mathrm{M}$ 8-Cl-Ado [2], indicating tumoricidal doses are readily achievable. Additionally, an extensive toxicology assessment of numerous hematology, clinical chemistry, and microscopic pathology parameters of 8-Cl-Ado treatment in CD1 mice showed no toxicity at these doses [36].

In the current study our results showed growth of the MCF-7 tumors were suppressed by the $100 \mathrm{mg} / \mathrm{kg}$ 8-Cl-Ado treatment (Figure 7A) which showed statistically significant differences by day 10 of treatment. Additionally, there was a dose dependent inhibition in a comparison of $0,25,50$, and $100 \mathrm{mg} / \mathrm{kg}$ doses (data not shown). The growth of BT-474 tumors was dramatically altered as growth was significantly inhibited by the third day of treatment (Figure 7B). Furthermore, many of the tumors showed regression with the $100 \mathrm{mg} / \mathrm{kg} 8$-Cl-Ado treatment. A $50 \mathrm{mg} / \mathrm{kg}$ dose did not affect the growth of the BT-474 xenograft tumors (data not shown). Similarly, an assessment of the final, excised tumor volume again showed mice treated with $100 \mathrm{mg} / \mathrm{kg} \mathrm{8-Cl-Ado} \mathrm{had} \mathrm{statistically}$ smaller MCF-7 and BT-474 tumor volumes after completion of the treatment (Figure 7C and D). Moreover, 9 of 20 BT-474 tumors completely regressed macroscopically. These results establish the potential for 8-Cl-Ado as a therapeutic agent to treat breast cancer and indicate BT-474 orthotopic tumors have a higher sensitivity to 8-Cl-Ado.

\section{Discussion}

Previously, our investigations on the cytotoxic effects of 8-Cl-Ado focused on the accumulation of 8-Cl-ATP and its inhibitory effects on transcription [2,8-10,12]. In breast cancer cells, 8-Cl-Ado-induced cytotoxicity is only partially attributed to apoptosis. Depletion of the intracellular ATP pool has been associated with apoptosis-independent cell death [23,24]. Since 8-Cl-Ado treatment diminishes the ATP pool (Figure 2A) [2,8-10,12], the objective of the current study was to further evaluate 8-Cl-Ado metabolic effects on the cells and its involvement with non-apoptotic cell death in the breast cancer cell lines. Data presented in the present work indicates 8-Cl-Ado perturbs bioenergy production in breast cancer cells by altering both glycolysis and mitochondrial respiration. The resulting ATP depletion induces AMPK activation, leading to an attenuation of mTOR signaling and an induction of autophagic cell death.

Previous evidence suggested that the mode by which 8-Cl-Ado leads to ATP depletion is due to the analog's metabolite, 8-Cl-ADP, being a substrate for ATP synthase for conversion to 8-Cl-ATP [28]. In that study, both the di and tri phosphate of 8-ClAdo were found to affect complex V, ATP synthase. Based on molecular modeling, 8-Cl-ATP was shown to fit well in the product site which 


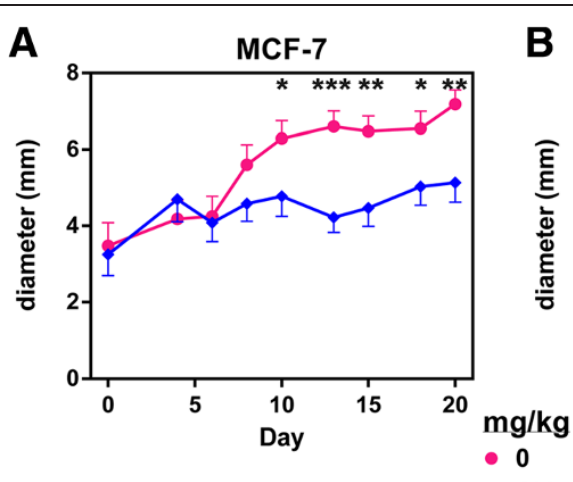

B BT-474

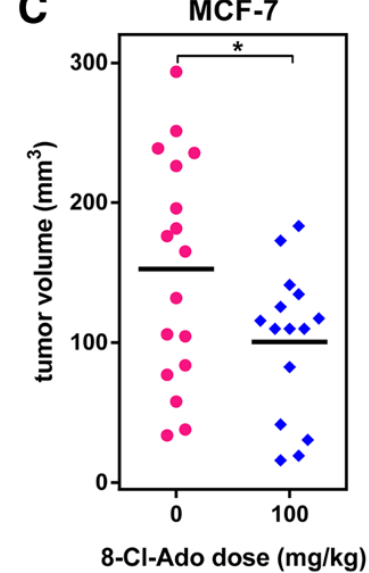

- 100
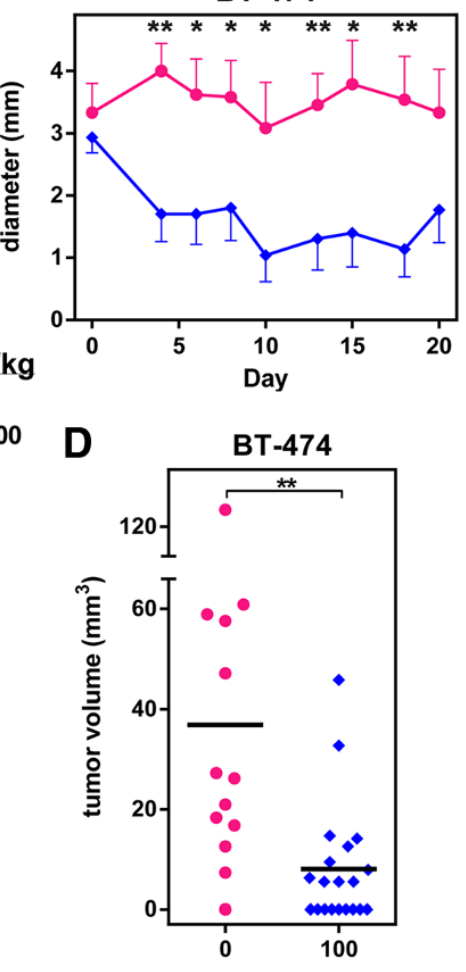

8-Cl-Ado dose $(\mathrm{mg} / \mathrm{kg})$

Figure 7 Efficacy of 8-Cl-Ado in breast cancer xenograft models. MCF-7 and BT474 xenografts in nude mice were established as described in Materials and Methods. Mice were treated with control PBS (0 mg/kg) or 8-Cl-Ado (100 mg/kg) three times a week for 3 weeks. MCF-7 (A) and BT-474 (B) tumor growth during 8-Cl-Ado treatment were assessed by measuring maximum tumor diameter each day of treatment. Final MCF-7 (C) and BT-474 (D) tumor volumes of tumors excised within 3 days of the final treatment. Statistical significance was determined using an unpaired t-test was used to, ${ }^{*} P<0.05,{ }^{* *} P<0.01,{ }^{* * *} P<0.001$.

is the "loose" binding conformation of $\mathrm{F}_{\mathrm{o}} \mathrm{F}_{1}$-ATP synthase catalytic site, thus inhibiting catalysis of its natural substrate ADP to synthesize ATP. Our evaluation of basal mitochondrial respiration in breast cancer cells treated with 8-Cl-Ado is in agreement with this study's finding on 8-Cl-Ado treatment inhibiting complex $\mathrm{V}$ activity.

Additionally, our data from the Mito Stress Test suggests 8-Cl-Ado also alters a component(s) of complex I-V of the electron transport chain complex (ETC) as well. This is in contrast to the prior study [28] which concluded 8-Cl-Ado treatment did not affect complex I-IV. Their premise was based on similar $\mathrm{O}_{2}$ consumption rate in cells treated with 8-Cl-Ado versus adenosine. While our analysis did not evaluate the effects of adenosine on these cells, our conclusions are based on the use of an uncoupler, FCCP, which allows complex I-V to work at full function even when complex $\mathrm{V}$ is inhibited. Under these conditions, the 8-Cl-Ado treated breast cancer cells still showed depressed rates of $\mathrm{O}_{2}$ consumption. One possible mechanism by which 8-Cl-Ado may be affecting the ETC is through disturbing the citric acid cycle. In MCL cells, 8-Cl-AMP was found to be metabolized to both 8-Cl-ATP and to succinyl-8-Cl-Ado [37]. The high metabolism to a succinylated moiety in MCL cells depleted fumarate, a component of the citric acid cycle. In MCL cells, the accumulation of succinyl-8-Cl-Ado was greater than 8-ClATP. While high accumulation of succinyl-8-Cl-AMP was not seen in MCF-7 or BT-474 cells as the levels of succinyl-8-Cl-Ado reached less than $10 \%$ of the 8-Cl-ATP levels (unpublished data), it does suggests 8-Cl-Ado may have some degree of an effect on the citric acid cycle in breast cancer cells. Additional studies are ongoing to determine what component(s) of the ETC is affected by 8-Cl-Ado treatment.

Besides metabolism to succinyl-8-Cl-Ado, the analog may be indirectly affecting ATP production through altering glycolysis. An 8-Cl-Ado congener compound, 8-aminoadenosine has been shown to alter the localization and expression of glucose transporters, and reduce glucose consumption, in myeloma cells [29]. Thus, it probable that 8-Cl-Ado may also be altering glycolysis in breast cancer cells through similar mechanisms.

In the breast cancer cells, we found the 8-Cl-Ado-mediated depletion of the endogenous cellular ATP pool 
was associated with an induction of AMPK phosphorylation and activity as measured by phosphorylation of AMPK target proteins, ACC and raptor. In agreement with our work, both Han et al. [38] and Lucchi et al. [39] showed that 8-chloro-cyclic AMP (8-Cl-cAMP) also activates AMPK. Our group and others have demonstrated that 8-Cl-cAMP serves as prodrug for 8-Cl-Ado, as the cyclic analog is converted extracellularly in plasma or in medium to 8-Cl-Ado via the enzymatic actions of serum phosphodiesterase and $5^{\prime}$-nucleotidase $[6,7,17,40]$. In concert, studies using an adenosine kinase deficient cell line demonstrated that 8-Cl-cAMP needs to be converted to 8-Cl-Ado and metabolized to 8-Cl-AMP intracellularly to induce its cytotoxic effects [9]. In both studies by Han et al. [38] and Lucchi et al. [39], the authors went on to further examine the growth inhibitory effects of 8-Cl-cAMP-induced AMPK activity on p38 mitogenactivated protein kinase to induce apoptosis. Both groups conclusively demonstrated that 8-Cl-cAMP mediated AMPK and p38 activation promoted the growth inhibitory and apoptotic effects of 8-Cl-cAMP, as combinations with the p38 inhibitors attenuated these events.

It is also interesting to note that while the induction of AMPK and autophagy occurred in both MCF-7 and BT-474 cells, the induction was not as robust in the BT-474 cells. For example, phosphorylation of ACC reached 3.8 fold increase in MCF-7 and 1.5 fold in BT474; flux in p62 levels in MCF-7 increased to 1.70 fold and then decreased down to 0.67 fold while in BT- 474 increased to 1.13 fold and then decreased down to 0.77 fold change. MCF-7 and BT-474 cells are p53 wild type and mutant [30], respectively; thus, the occurrence of AMPK and autophagy induction in both cell lines indicates these events do not require p53. However, since there was less induction in BT-474 cells, this may suggest there might be some dependency on p53 to achieve the same level of induction as seen in MCF-7 cells. Though this notion is intriguing, additional studies would be needed to explore the possibility of p53 status playing a role in the differential induction levels. A study of 8amino-adenosine in breast cancer cell lines MCF-7 and MDA-MB-231 (p53 mutant) cell lines also showed this analog was able to induce apoptosis and autophagy in both cell lines, though the mechanism for the autophagy induction was not examined [41]. Moreover, in agreement with our work, this study showed that inhibition of autophagy did not affect the level of apoptosis. Because clonogenic survival was not examined in this study, it is unclear if the inhibition of autophagy affected this survival.

Agents with AMPK agonist activity have generated considerable interest for use in cancer therapeutics [reviewed in [25]]. The diabetes drug, metformin, is believed to be an oxidative phosphorylation inhibitor that induces
AMPK through its ability to decrease ATP levels. Metformin has been shown to suppress spontaneous tumor formation in various animal models as well as suppress in vitro and in vivo tumor growth. Moreover, several studies have shown metformin reduces cancer risks in diabetic patients as well as improved therapeutic response in those with breast cancer. Interestingly, in vivo studies in mouse model systems indicate both p53 deficient [42] and HER2 over expressing tumor cells [43] have an increased sensitivity to metformin treatment. Similarly, we demonstrated 8-Cl-Ado had the highest efficacy in the BT-474 xenograft tumors which are both p53 deficient and HER2 over expressing. While 8-Cl-Ado inhibited the growth of both MCF-7 and BT-474 xenograft tumors, $45 \%$ of the BT-474 tumors were no longer detectable macroscopically after a 3 week treatment with $100 \mathrm{mg} / \mathrm{kg}$ dose.

A study by Cheong et al. demonstrated that metformin in combination with the glycolysis inhibitor, 2-deoxyglucose, activated AMPK, inhibited mTORC1 and induced autophagy [23]. Furthermore, the authors stated that in 13 of 15 cancer cell lines tested, this combination was more cytotoxic than either agent alone. Moreover, the increased sensitivity of this couplet correlated with ATP depletion and was associated with the down regulation of the expression of key components of the ETC complex I. In contrast, combination of AICAR and 2-deoxyglucose was also able to activate AMPK and inhibit mTORC1 but was not cytotoxic and did not deplete ATP. This was attributed to increased expression of numerous genes in ETC I, II, III, IV and $\mathrm{F}_{\mathrm{o}} \mathrm{F}_{1}$-ATP synthase complexes, which would promote ATP production. Although Cheong et al. did not evaluate autophagy in the AICAR treated cells, it is important to point out there is controversy as to whether AICAR promotes or inhibits autophagy [44-46]. Their results do indicate a superior therapeutic effect is achieved with a dual inhibition of energy pathways for targeting tumor bioenergetics. Based on our findings that 8-Cl-Ado is able to perturb glycolysis as well as deplete ATP it is interesting to speculate this ribonucleoside analog, as a single agent, may achieve the dual effects seen with metformin and 2-deoxy-glucose combination.

\section{Conclusion}

In summary, we show that 8-Cl-Ado is cytotoxic to breast cancer cells and this cytotoxicity is mediated by both apoptosis and autophagy. The 8-Cl-Ado-induced depletion of ATP elicits the autophagic response through activation of AMPK and inhibition of MTORC1; with the endpoint of these events being the activation of an autophagy initiation factor, ULK1, leading to the induction of autophagy. This unique nucleoside analog is in a phase I clinical trial for hematological malignancies. Preliminary analysis of the cells from patients in the trial indicates ATP depletion, AMPK activation, and induction of autophagy occurs 
while the patients are undergoing treatment with 8-Cl-Ado (unpublished data). Taken together our results indicate that targeting the bioenergy production of breast cancer cells would be an effective strategy for treating this disease, which can be readily achieved with 8-Cl-Ado.

\section{Methods \\ Materials}

8-Cl-Ado was obtained from Dr. V. Rao at the Drug Development Branch of the National Cancer Institute and was dissolved in water. Rapamycin (LC Laboratories, Woburn, MA) and bafilomycin A1 (Baf) (Sigma-Aldrich, St. Louis, MO) were dissolved in DMSO.

\section{Cell culture, clonogenic assays, and transfection}

MCF-7 and BT-474 cell lines were obtained from ATCC (Manassas, VA) and maintained in DMEM:F12 (Mediatech, Manassas, VA) supplemented with $10 \%$ fetal bovine serum in the presence of $5 \% \mathrm{CO}_{2}$ at $37^{\circ} \mathrm{C}$. Cells were routinely tested for Mycoplasma infection and were authenticated by short tandem repeat analysis by UT MD Anderson Cancer Center's Characterized Cell Line Core facility. Colony formation assays were performed as described [2].

siRNA transfections were performed with ON-TARGETplus siATG7, siBECN1 SMARTpool or ON-TARGETplus siCONTROL (siCONT) (Dharmacon, Lafayette, CO). Dharmafect 4 was used to transfect $1.5 \times 10^{6}$ MCF-7 cells with 600 pmoles siRNA as per the manufacturer's protocol (Dharmacon). Expression knockdown was allowed to proceed for $\sim 2$-days before reseeding for treatment analysis. GFP-LC3 expression construct was obtained from Dr. Gordon Mills in the Department of Systems Biology, UT MD Anderson Cancer Center. Using Nucleofector Kit V, programs P-20 and T-20, respectively, (Amaxa Biosystems, Koeln, Germany), $2 \times 10^{6}$ MCF-7 and BT-474 cells were transfected with $2 \mu \mathrm{g}$ DNA. After transfection, cells were cultured for 1-day prior to selection with $500 \mu \mathrm{g} / \mathrm{ml} \mathrm{G} 418>4$ weeks to obtain pools of stably transfected GFP-LC3 expressing cells.

\section{Measurement of glycolysis, oxygen consumption, and intracellular NTPs}

OCR was measured using XF 96 Extracellular Analyzer instrument (Seahorse Bioscience Inc., Chicopee, MA). MCF7 and BT474 cells were plated at 30,000 cells per well on XF96 cell culture microplate in $100 \mu$ l of culture media. Cells were treated with $10 \mu \mathrm{M}$ 8-Cl-Ado for $18 \mathrm{hrs}$. Media was then replaced with fresh XF assay medium (Seahorse Bioscience Inc.), supplemented with $17.5 \mathrm{mM}$ Glucose and $2 \mathrm{mM}$ Sodium Pyruvate, $(175 \mu \mathrm{l} /$ well $)$ and is incubated in a $\mathrm{CO}_{2}$ free chamber of XF Prep station for $1 \mathrm{hr}$. XF Cell Mito Stress Test assay was performed as per the manufacturer's instructions using the following final concentrations; $1.25 \mu \mathrm{M}$ oligomycin, $1 \mu \mathrm{M}$ FCCP, $0.75 \mu \mathrm{M}$ antimycin and $1.25 \mu \mathrm{M}$ rotenone (Seahorse Bioscience Inc.). Each assay was repeated at least twice. For ECAR, the culture media was replaced with glycolysis stress test media (prepared in accordance with Seahorse Glycolysis stress kit) supplemented with $2 \mathrm{mM}$ of fresh L-Glutamine. For the glycolysis assay, all ports were injected with $25 \mu \mathrm{l}$ of drugs for the following final concentrations; Port A-10 mM glucose, Port B -1.25 oligomycin, Port C$100 \mathrm{mM}$ 2-deoxyglucose.

Perchloric acid was used to extract NTPs from MCF-7 and BT-474 cells treated with $10 \mu \mathrm{M} 8-\mathrm{Cl}$-Ado and neutralized extracts were analyzed by HPLC (Waters 600E System Controller; Waters Corp., Milford, MA, USA) as described [2].

\section{Flow cytometry}

Analysis of annexin $\mathrm{V}$ and PI labeling was performed as described [2]. To detect and quantify the development of 8-Cl-Ado-induced AVO, treated and untreated MCF-7 and BT-474 cells were stained directly in culture with $1 \mu \mathrm{g} / \mathrm{ml}$ acridine orange (Invitrogen) for 15 minutes at $37^{\circ} \mathrm{C}$ essentially as described [47]. Thirty minutes prior to staining, $0.1 \mu \mathrm{g} / \mathrm{ml}$ Baf was added to a duplicate culture of 8-Cl-Ado treated cells as a control for negative AVO staining. Cells treated with $50 \mathrm{nM}$ rapamycin were used as a positive control. Cells were removed from the plate with Accumax (Fisher Scientific) and combined with pellets of cells detached during treatment, then analyzed using a Becton Dickinson FACSCalibur flow cytometer and CellQuest software (San Jose, CA, USA).

\section{Immunoblot analysis}

Exponentially growing cells were treated with $10 \mu \mathrm{M}$ 8-Cl-Ado for various amounts of time and protein lysates were isolated and analyzed using an Odyssey Infrared Imaging System (LI-COR Biosciences) as described [19]. Primary antibodies were rabbit polyclonal antibodies against p-AMPKa (Thr172), AMPKa, p-acetyl-coA carboxylase (ACC) (Ser79), p-raptor (Ser792), p-mTOR (Ser2481), p4EBP1 (Ser65) (Cell Signaling Technology), LC3B, beclin 1 (Novus Biologicals, Inc, Littleton, CO), p62 (Enzo Life Sciences, Farmingdale, NY); rabbit monoclonal antibodies against p-ULK1 (Ser555) clone D1H4, raptor clone 24C12, mTOR clone 7C10 (Cell Signaling Technology), ATG7 (Novus Biologicals, Inc, Littleton, CO); mouse monoclonal antibodies GAPDH clone 6C6 (Abcam, Inc, Cambridge, MA); and goat polyclonal antibody 4E-BP1 (Santa Cruz Biotechnology, Inc, Santa Cruz, CA).

\section{Microscopic labeling of autophagic vesicles}

MCF-7 cells were seeded overnight into 4 well chamber slides at a density of $1.5 \times 10^{4}$ cells/chamber followed by a 72 -hours treatment with or without either $10 \mu \mathrm{M}$ 
8-Cl-Ado or $50 \mathrm{nM}$ rapamycin. AVO were stained by incubating cells in $50 \mathrm{mM} \mathrm{MDC}$ (Sigma-Aldrich) in PBS at $37^{\circ} \mathrm{C}$ for 10 minutes and then washed three times with PBS. Nuclei were counter stained with $5 \mu \mathrm{M}$ SYTO 61 (Invitrogen) in Tris-buffered saline ( $25 \mathrm{mM}$ Tris, $150 \mathrm{mM}$ $\mathrm{NaCl}, \mathrm{pH} 7.5)$ at $37^{\circ} \mathrm{C}$ for 10 minutes and then washed twice with PBS and immediately analyzed at UT MD Anderson Cancer Center's Flow Cytometry and Cellular Imaging Core Facility by fluorescence microscopy using an inverted microscope (Olympus 1X71, Melville, NY) equipped with a filter system (excitation filter: $350 / 50 \mathrm{~nm}$, emission filter: 528/38 nm). Images were obtained with a Hamamatsu Orca II ER camera (Hamamatsu, Japan) and processed using the program Slidebook (3I, Denver, CO).

\section{Xenograft studies}

MCF-7 and BT474 xenografts were established in 4- 6week-old nu/nu female athymic nude mice (Department of Experimental Radiation Oncology Animal Facility, The University of Texas MD Anderson Cancer Center) supplemented with $0.72 \mathrm{mg} 60$-day release $17 \beta$-estrogen pellets (Innovative Research of America, Sarasota, FL) by inoculating $5 \times 10^{6}$ MCF-7 cells or $1 \times 10^{7}$ BT474 cells into two sites of the mammary fat pads $[48,49]$. When maximum tumor diameters reached $\sim 3 \mathrm{~mm}$, the animals were randomly allocated (8-10 mice per group) for a 3 weeks i.p. treatment with 8-Cl-Ado dissolved in PBS (0 or $100 \mathrm{mg} / \mathrm{kg}, 3$ days/week). Body weight and tumor growth were assessed 3 days/week and maximum tumor diameters were recorded. Shortly after the end of the treatment (1-3 days), the mice were sacrificed, tumors were collected and tumor volumes were calculated in $\mathrm{mm}^{3}$ using the formula length $\times$ width $\times$ height $\times \pi / 6$. All experiments involving animals were performed in accordance with the guidelines of the Institutional Animal Care and Use Committee.

\section{Statistical analysis}

All graphing, statistical, and regression analysis was performed using Prism software (GraphPad Software, San Diego, CA). The elimination of 8-Cl-ATP was examined by one phase and two phase decay nonlinear regression analysis.

\section{Additional file}

Additional file 1: Figure S1. Effect of 8-Cl-Ado on the survival of breast cancer cells. Figure S2: Accumulation of 8-Cl-ATP and effects on ATP production. Figure S3: 8-Cl-Ado-induces autophagy.

\section{Abbreviations}

8-Cl-Ado: 8-chloro-adenosine; 8-Cl-cAMP: 8-Cl-cyclic AMP; AMPK: AMP-activated protein kinase; AVO: Acidic vesicular organelles; Baf: Bafilomycin A1; CLL: Chronic lymphocytic leukemia; ECAR: Extracellular acidification rate; ETC: Electron transport chain complex; FCCP: Trifluorocarbonylcyanide phenylhydrazone; GFP: Green fluorescent protein; LC3B: Microtubuleassociated protein 1 light chain 3B; MCL: Mantle cell lymphoma; MDC: Monodansylcadaverine; mTOR: Mammalian target of rapamycin; OCR: Oxygen consumption rate; p: Phospho; PI: Propidium iodide; siRNA: Small interfering RNA; Ulk1: Unc51-like kinase 1.

\section{Competing interest}

The authors declare that they have no competing interest.

\section{Authors' contributions}

CMS wrote the manuscript, performed transfections experiments, immunoblot, HPLC, mouse xenograft, flow cytometry and microscopic analyses, analyzed and designed all experiments; HVP performed and analyzed glycolysis and aerobic respiration analysis; XFL and WM provided assistance and guidance in mouse xenograft studies; SS performed immunoblot and mouse xenograft analysis and prepared samples for HPLC and flow cytometry. All authors read and approved the final manuscript.

\section{Acknowledgments}

This work was supported by a Career Catalyst Award, KG080366, from Susan G. Komen for the Cure and by a Cancer Center Support Grant, P50 CA16672, from the National Cancer Institute, Department of Health and Human Services.

The authors thank Drs. Lisa S. Chen and Varsha Gandhi for critically reviewing this manuscript, Dr. Gordon Mills for generously providing the GFP-LC3 expression construct, and Dr. Jared K. Burks for advice on staining for confocal microscopy studies.

Received: 17 February 2014 Accepted: 11 March 2014 Published: 14 March 2014

\section{References}

1. Schaapveld M, Visser O, Louwman MJ, de Vries EG, Willemse PH, Otter R, van der Graaf WT, Coebergh JW, van Leeuwen FE: Risk of new primary nonbreast cancers after breast cancer treatment: a Dutch population-based study. J Clin Oncol 2008, 26:1239-1246.

2. Stellrecht CM, Ayres M, Arya R, Gandhi V: A unique RNA-directed nucleoside analog is cytotoxic to breast cancer cells and depletes cyclin $\mathrm{E}$ levels. Breast Cancer Res Treat 2010, 121:355-364.

3. Lange-Carter CA, Vuillequez JJ, Malkinson AM: 8-Chloroadenosine mediates 8-chloro-cyclic AMP-induced down-regulation of cyclic AMP-dependent protein kinase in normal and neoplastic mouse lung epithelial cells by a cyclic AMP-independent mechanism. Cancer Res 1993, 53:393-400.

4. Zhang HY, Gu YY, Li ZG, Jia YH, Yuan L, Li SY, An GS, Ni JH, Jia HT: Exposure of human lung cancer cells to 8-chloro-adenosine induces $\mathrm{G} 2 / \mathrm{M}$ arrest and mitotic catastrophe. Neoplasia 2004, 6:802-812.

5. Zhu B, Zhang LH, Zhao YM, Cui JR, Strada SJ: 8-chloroadenosine induced $\mathrm{HL}-60$ cell growth inhibition, differentiation, and $\mathrm{G}(0) / \mathrm{G}(1)$ arrest involves attenuated cyclin D1 and telomerase and up-regulated p21(WAF1/CIP1). J Cell Biochem 2006, 97:166-177.

6. Taylor CW, Yeoman LC: Inhibition of colon tumor cell growth by 8-chloro-cAMP is dependent upon its conversion to 8-chloro-adenosine. Anticancer Drugs 1992, 3:485-491.

7. Van Lookeren Campagne MM, Villalba Diaz F, Jastorff B, Kessin RH: 8-Chloroadenosine $3^{\prime}, 5^{\prime}$-monophosphate inhibits the growth of Chinese hamster ovary and Molt-4 cells through its adenosine metabolite. Cancer Res 1991, 51:1600-1605.

8. Dennison JB, Balakrishnan K, Gandhi V: Preclinical activity of 8-chloroadenosine with mantle cell lymphoma: roles of energy depletion and inhibition of DNA and RNA synthesis. Br J Haematol 2009, 147:297-307.

9. Gandhi V, Ayres M, Halgren RG, Krett NL, Newman RA, Rosen ST: 8-chloro-cAMP and 8-chloro-adenosine act by the same mechanism in multiple myeloma cells. Cancer Res 2001, 61:5474-5479.

10. Stellrecht CM, Rodriguez CO Jr, Ayres M, Gandhi V: RNA-directed actions of 8-chloro-adenosine in multiple myeloma cells. Cancer Res 2003, 63:7968-7974.

11. Ghias K, Ma C, Gandhi V, Platanias LC, Krett NL, Rosen ST: 8-Amino-adenosine induces loss of phosphorylation of p38 mitogen-activated protein kinase, extracellular signal-regulated kinase $1 / 2$, and Akt kinase: role in induction of apoptosis in multiple myeloma. Mol Cancer Ther 2005, 4:569-577. 
12. Balakrishnan K, Stellrecht CM, Genini D, Ayres M, Wierda WG, Keating M, Leoni LM, Gandhi V: Cell death of bioenergetically compromised and transcriptionally challenged CLL lymphocytes by chlorinated ATP. Blood 2005, 105:4455-4462.

13. Langeveld CH, Jongenelen CA, Theeuwes JW, Baak JP, Heimans JJ, Stoof JC, Peters GJ: The antiproliferative effect of 8-chloro-adenosine, an active metabolite of 8-chloro-cyclic adenosine monophosphate, and disturbances in nucleic acid synthesis and cell cycle kinetics. Biochem Pharmacol 1997, 53:141-148.

14. Langeveld CH, Jongenelen CA, Heimans JJ, Stoof JC: 8-Chloro-cyclic adenosine monophosphate, a novel cyclic AMP analog that inhibits human glioma cell growth in concentrations that do not induce differentiation. Exp Neurol 1992, 117:196-203.

15. Langeveld CH, Jongenelen CA, Heimans JJ, Stoof JC: Growth inhibition of human glioma cells induced by 8-chloroadenosine, an active metabolite of 8-chloro cyclic adenosine 3':5'-monophosphate. Cancer Res 1992 52:3994-3999

16. Krett NL, Zell JL, Halgren RG, Pillay S, Traynor AE, Rosen ST: Cyclic adenosine-3', $5^{\prime}$-monophosphate-mediated cytotoxicity in steroid sensitive and resistant myeloma. Clin Cancer Res 1997, 3:1781-1787.

17. Halgren RG, Traynor AE, Pillay S, Zell JL, Heller KF, Krett NL, Rosen ST: 8CI-cAMP cytotoxicity in both steroid sensitive and insensitive multiple myeloma cell lines is mediated by 8Cl-adenosine. Blood 1998, 92:2893-2898.

18. Carlson CC, Chinery R, Burnham LL, Dransfield DT: 8-Cl-adenosine-induced inhibition of colorectal cancer growth in vitro and in vivo. Neoplasia 2000, 2:441-448.

19. Stellrecht CM, Phillip CJ, Cervantes-Gomez F, Gandhi V: Multiple myeloma cell killing by depletion of the MET receptor tyrosine kinase. Cancer Res 2007, 67:9913-9920.

20. Gandhi V, Chen W, Ayres M, Rhie JK, Madden TL, Newman RA: Plasma and cellular pharmacology of 8-chloro-adenosine in mice and rats. Cancer Chemother Pharmacol 2002, 50:85-94.

21. Chen LS, Du-Cuny L, Vethantham V, Hawke DH, Manley JL, Zhang S, Gandhi $V$ : Chain termination and inhibition of mammalian poly(A) polymerase by modified ATP analogues. Biochem Pharmacol 2010, 79:669-677.

22. Chen $L S$, Sheppard TL: Chain termination and inhibition of Saccharomyces cerevisiae poly(A) polymerase by C-8-modified ATP analogs. J Biol Chem 2004, 279:40405-40411.

23. Cheong J-H, Park ES, Liang J, Dennison JB, Tsavachidou D, Nguyen-Charles C, Wa Cheng K, Hall H, Zhang D, Lu Y, Ravoori M, Kundra V, Ajani J, Lee J-S, Ki Hong W, Mills GB: Dual inhibition of tumor energy pathway by 2deoxyglucose and metformin is effective against a broad spectrum of preclinical cancer models. Mol Cancer Ther 2011, 10:2350-2362.

24. Schafer ZT, Grassian AR, Song L, Jiang Z, Gerhart-Hines Z, Irie HY, Gao S, Puigserver P, Brugge JS: Antioxidant and oncogene rescue of metabolic defects caused by loss of matrix attachment. Nature 2009, 461:109-113.

25. Shackelford DB, Shaw RJ: The LKB1-AMPK pathway: metabolism and growth control in tumour suppression. Nat Rev Cancer 2009, 9:563-575.

26. Mihaylova MM, Shaw RJ: The AMPK signalling pathway coordinates cell growth, autophagy and metabolism. Nat Cell Biol 2011, 13:1016-1023.

27. Kim J, Kim YC, Fang C, Russell RC, Kim JH, Fan W, Liu R, Zhong Q, Guan KL: Differential regulation of distinct Vps34 complexes by AMPK in nutrient stress and autophagy. Cell 2013, 152:290-303.

28. Chen LS, Nowak BJ, Ayres ML, Krett NL, Rosen ST, Zhang S, Gandhi V: Inhibition of ATP synthase by chlorinated adenosine analogue. Biochem Pharmacol 2009, 78:583-591.

29. Shanmugam M, McBrayer SK, Qian J, Raikoff K, Avram MJ, Singhal S, Gandhi V, Schumacker PT, Krett NL, Rosen ST: Targeting glucose consumption and autophagy in myeloma with the novel nucleoside analogue 8-aminoadenosine. J Biol Chem 2009, 284:26816-26830.

30. Bartek J, lggo R, Gannon J, Lane DP: Genetic and immunochemical analysis of mutant p53 in human breast cancer cell lines. Oncogene 1990, 5:893-899.

31. Sun S-Y, Rosenberg LM, Wang X, Zhou Z, Yue P, Fu H, Khuri FR: Activation of Akt and elF4E survival pathways by rapamycin-mediated mammalian target of rapamycin inhibition. Cancer Res 2005, 65:7052-7058.

32. Bach M, Larance M, James DE, Ramm G: The serine/threonine kinase ULK1 is a target of multiple phosphorylation events. Biochem J 2011, 440:283-291.

33. Egan DF, Shackelford DB, Mihaylova MM, Gelino S, Kohnz RA, Mair W, Vasquez DS, Joshi A, Gwinn DM, Taylor R, Asara JM, Fitzpatrick J, Dillin A, Viollet B, Kundu M, Hansen M, Shaw RJ: Phosphorylation of ULK1 (hATG1) by AMP-activated protein kinase connects energy sensing to mitophagy. Science 2011, 331:456-461.
34. Tripathi DN, Chowdhury R, Trudel L, Tee AR, Slack RS, Walker CL, Wogan GN: Reactive nitrogen species regulate autophagy through ATM-AMPKTSC2-mediated suppression of mTORC1. Proc Natl Acad Sci U S A 2013, 110:E2950-E2957.

35. Wirth M, Joachim J, Tooze SA: Autophagosome formation-the role of ULK1 and Beclin1-PI3KC3 complexes in setting the stage. Semin Cancer Biol 2013, 23:301-309.

36. Stellrecht CM, Shentu S, Gandhi V: In vivo activity of the ribonucleoside analog, 8-chloro-adenosine, in breast cancer mouse models. Proceedings AACR 2013, 52:5506.

37. Dennison JB, Ayres ML, Kaluarachchi K, Plunkett W, Gandhi V: Intracellular succinylation of 8-chloroadenosine and its effect on fumarate levels. J Biol Chem 2010, 285:8022-8030

38. Han JH, Ahn YH, Choi KY, Hong SH: Involvement of AMP-activated protein kinase and p38 mitogen-activated protein kinase in 8-Cl-cAMP-induced growth inhibition. J Cell Physiol 2009, 218:104-112.

39. Lucchi S, Calebiro D, de Filippis T, Grassi ES, Borghi MO, Persani L: 8-Chloro-cyclic AMP and protein kinase A I-selective cyclic AMP analogs inhibit cancer cell growth through different mechanisms. PloS one 2011, 6:e20785.

40. Stellrecht CM, Krett N, Ayres M, Rosen S, Gandhi V: 8-chloro-cAMP serves as a prodrug for the RNA directed nucleoside analog, 8-chloro-adenosine. In Acute leukemia IX: Basic Research, Experimental Approaches and Novel Therapies. Volume 9. Edited by Hiddemann W, Büchner T, Ritter J, Unterhalt M, Haferlach T. Heidelberg, Germany: Springer; 2003:193-199.

41. Polotskaia A, Hoffman S, Krett NL, Shanmugam M, Rosen ST, Bargonetti J: 8-Amino-adenosine activates $\mathrm{p} 53$-independent cell death of metastatic breast cancers. Mol Cancer Ther 2012, 11:2495-2504.

42. Buzzai M, Jones RG, Amaravadi RK, Lum JJ, DeBerardinis RJ, Zhao F, Viollet B, Thompson CB: Systemic treatment with the antidiabetic drug metformin selectively impairs p53-deficient tumor cell growth. Cancer Res 2007, 67:6745-6752.

43. Zhu P, Davis M, Blackwelder A, Bachman N, Liu B, Edgerton S, Williams LL, Thor $A D$, Yang $X$ : Metformin selectively targets tumor initiating cells in erbB-2 overexpressing breast cancer models. Cancer Prevention Research 2014, 7:199-210.

44. Lee JW, Park S, Takahashi Y, Wang H-G: The association of AMPK with ULK1 regulates autophagy. PloS one 2010, 5:e15394.

45. Liang J, Shao SH, Xu ZX, Hennessy B, Ding Z, Larrea M, Kondo S, Dumont DJ, Gutterman JU, Walker CL, Slingerland JM, Mills GB: The energy sensing LKB1-AMPK pathway regulates p27(kip1) phosphorylation mediating the decision to enter autophagy or apoptosis. Nat Cell Biol 2007, 9:218-224.

46. Meley D, Bauvy C, Houben-Weerts JH, Dubbelhuis PF, Helmond MT, Codogno P, Meijer AJ: AMP-activated protein kinase and the regulation of autophagic proteolysis. J Biol Chem 2006, 281:34870-34879.

47. Kanzawa $T$, Kondo $Y$, Ito H, Kondo $S$, Germano I: Induction of autophagic cell death in malignant glioma cells by arsenic trioxide. Cancer Res 2003, 63:2103-2108

48. Wen XF, Yang G, Mao W, Thornton A, Liu J, Bast RC Jr, Le XF: HER2 signaling modulates the equilibrium between pro- and antiangiogenic factors via distinct pathways: implications for HER2-targeted antibody therapy. Oncogene 2006, 25:6986-6996.

49. Le XF, Vallian S, Mu ZM, Hung MC, Chang KS: Recombinant PML adenovirus suppresses growth and tumorigenicity of human breast cancer cells by inducing G1 cell cycle arrest and apoptosis. Oncogene 1998, 16:1839-1849.

doi:10.1186/1756-8722-7-23

Cite this article as: Stellrecht et al:: ATP directed agent, 8-chloro-adenosine, induces AMP activated protein kinase activity, leading to autophagic cell death in breast cancer cells. Journal of Hematology \& Oncology 2014 7:23. 